\title{
A patient with one limb interstitial myositis with localised lipoatrophy presenting with severe cramps and fasciculations
}

\author{
Alain Créange, Jean-Luc Renard, Pierre Millet, Sylvie Boisnic, Dominique Felten, \\ Daniel Béquet, Jean-Jacques Hauw
}

\begin{abstract}
A case of interstitial myositis associated with a localised lipoatrophy is reported. The patient is a 24 year old man who presented with severe painful cramps and fasciculations localised to one limb. The rarity of both disorders, and their likely common autoimmune mechanism, suggest that this is not a chance association.
\end{abstract}

$(\mathcal{F}$ Neurol Neurosurg Psychiatry 1994;57:1541-1543)

Focal histopathological changes, such as panniculitis, appear rarely in patients with myositis. Exceptionally, such changes may be associated with cramps and fasciculations. ${ }^{1}$ We report a case of interstitial myositis with localised lipoatrophy, presenting with cramps and fasciculations, without previous clinical panniculitis.

Lipodystrophy is a rare condition, presenting as a loss of subcutaneous fat, that may occur in total, partial, or localised form. ${ }^{2}$ Total lipodystrophy can be congenital or acquired, and is usually associated with clinical features including hepatomegaly, dyslipidaemia, hyperpigmentation, diabetes mellitus, and glomerulonephritis. ${ }^{2}$ In partial lipodystrophy, the loss of subcutaneous fat usually spares the legs. The cause is unknown. It is usually sporadic, but may be transmitted as an autosomal dominant trait. Localised lipodystrophy, or lipoatrophy, is a different syndrome: scattered atrophic areas with loss of subcutaneous fat may be due to various conditions such as withdrawal of steroid treatment, insulin injections, trauma, or sequels of panniculitis in connective tissue diseases (for a review see Commens et $a l^{1}$ ). An association of lipodystrophy with scleroderma, idiopathic thrombocytopenic purpura, Hashimoto's thyroiditis, and juvenile rheumatoid arthritis has been occasionally reported, ${ }^{2}$ and an association with a focal interstitial myositis has been reported in two cases. $^{34}$

\section{Case report}

A 24 year old man was admitted for evaluation of cramps. He had had painful cramps in the anterior part of the right thigh and calf for 16 months. These occurred at rest and during sleep, and were elicited by movements. The patient noticed an atrophy of the entire right leg and an alopecia in the same area. Examination showed spontaneous thigh and calf fasciculations and cramps of the quadriceps femoris muscle. Movements and muscle percussion induced fasciculations and contractures. Muscle strength and sensory examination were normal. The right patellar reflex was faint. The right thigh diameter was 42.5 $\mathrm{cm}$ and the left diameter was $46 \mathrm{~cm}$ (fig 1A). There was an alopecia, complete on the right thigh and partial on the right calf. The subcutaneous fat of large parts of the right lower limb including the buttock was absent on skin examination. There was a round area of skin hyperpigmentation on the right thigh (fig 1A) and subcutaneous vessels were visible. There was no skin hardness or limb retraction. The skin was freely mobile over subcutaneous tissues. Normal laboratory findings included standard laboratory investigations, serologies for HIV, HTLV1, and Borrelia burgdorferi. Serum antinuclear antibody titre was $1 / 160$ and rheumatoid factors were 1/64. Examination by needle EMG showed spontaneous isolated and sometimes complex bursts of repetitive discharges in the right quadriceps femoris muscle. Cramps corresponded to high frequency motor unit discharges at 50 impulses per second. Fibrillations, positive waves, electrical myokymia, continuous muscle activity at rest, nerve hyperexcitability, and myotonic discharge at needle insertion were absent. There were normal motor units during voluntarily contraction of muscles. Motor and sensory conduction velocities and latencies were normal. Sensory evoked potential amplitudes were low in both peroneal nerves. The effects of limb ischaemia, regional curare test, nerve block, and repetitive nerve stimulations were not studied. Cerebral and spinal MRI were normal. Computed tomography showed atrophy of muscle and subcutaneous fat of the thigh (figures B and C). A course of carbamazepine (600 mg per day) resulted in an excellent improvement. Cramps and contractures nearly disappeared and clusters of fasciculations occurred only once a day. Four months 
(A) Anterior view of the patient showing global atrophy of the right leg and thigh. Arrows indicate the area of skin

hyperpigmentation. (B) and (C) $C T$ transverse sections of the thighs of the patient; (B) right; (C) left. Loss of subcutaneous fat is seen in $B$ (arrows). (D) Skin biopsy. Mild cell infiltration by mononuclear cells, and arrectores pilorum muscles apparently situated in the middle to upper dermis are seen (paraffin embedding; haematoxylin-eosin stain originally $\times 140) .(E)$ Quadriceps femoris muscle biopsy showing perivascular cuffs of mononuclear cells extending to the muscle interstitium, without necrosis of muscle cells (cryocut section; haematoxylin-eosin stain originally $\times 350$ ).
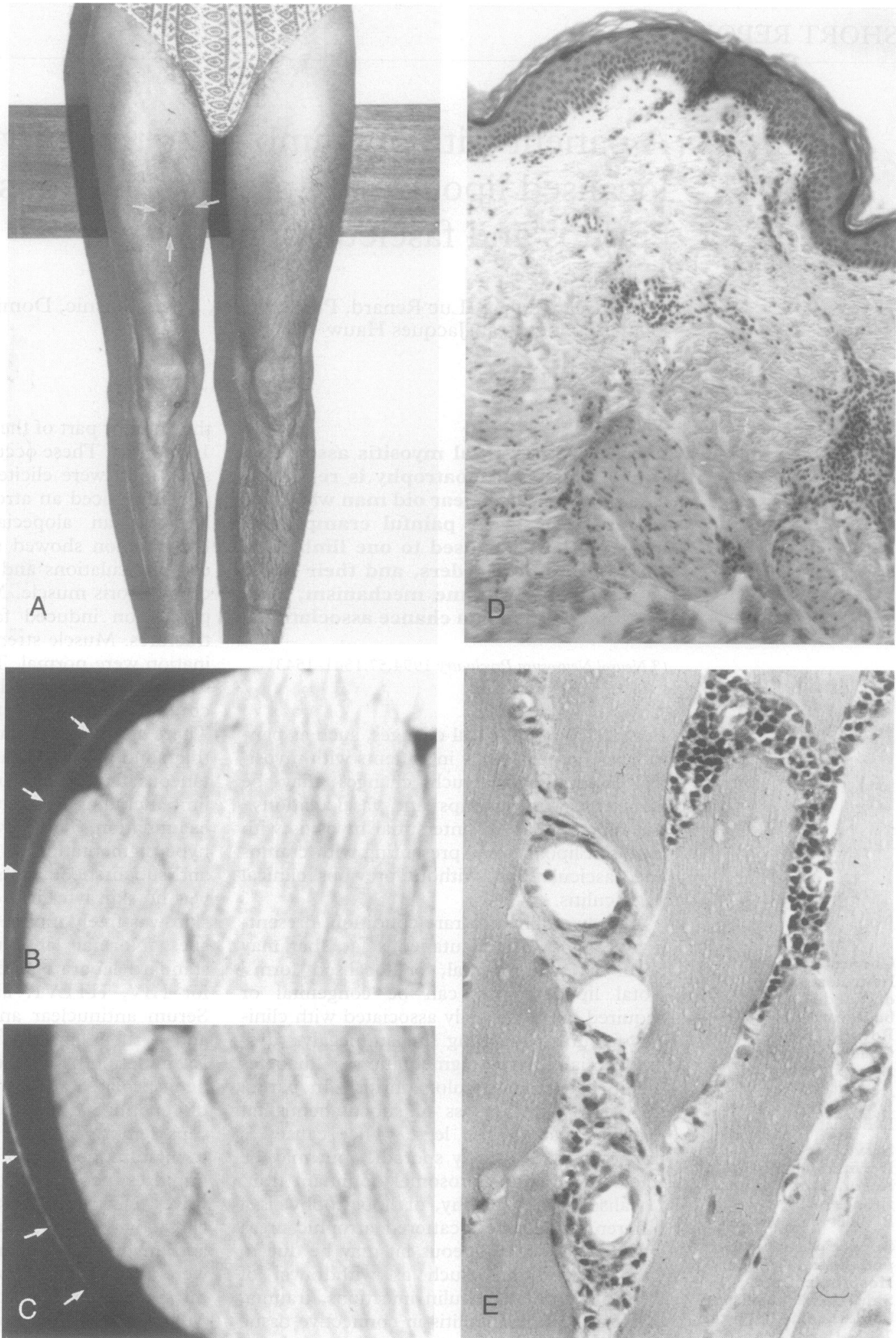

later, we noted an annular hyperpigmented plaque with central atrophy of subcutaneous fat on the left thigh. On the right thigh, the subcutaneous fat had partially reappeared.

HISTOPATHOLOGY

A skin biopsy, performed on the right thigh, showed mild perivascular lymphocyte infiltration. Collagen fibres appeared atrophic. Arrectores pilorum muscles were apparently situated in the mid to upper dermis (figure,

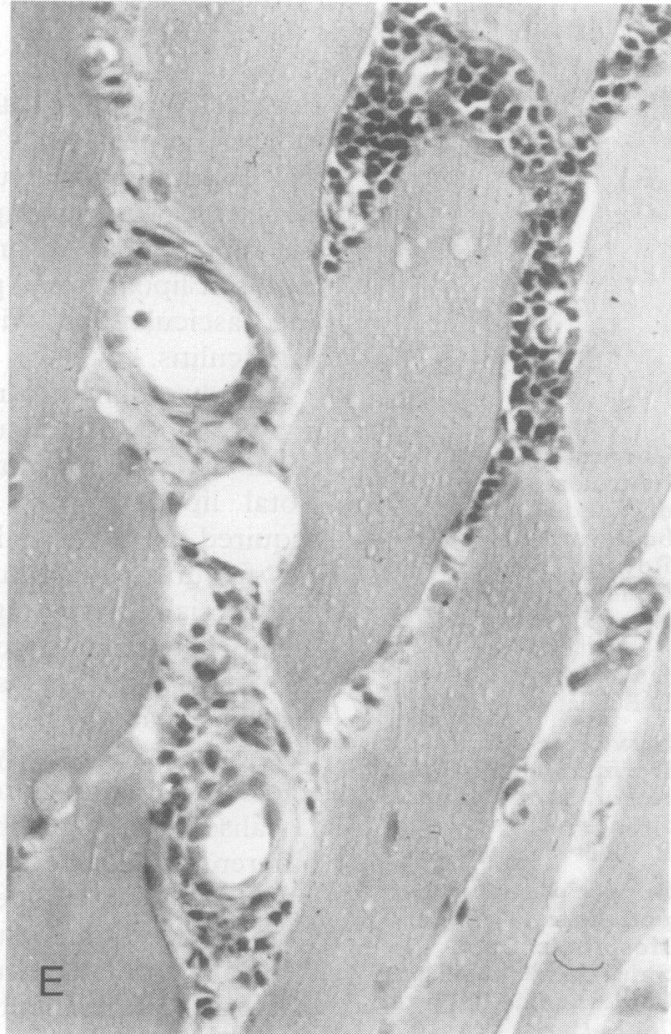

D). A right quadriceps femoris muscle biopsy showed a pronounced infiltration of the internating in the walls of small vessels, and around them (figure, E). No involvement of middle sized arteries or fibrinoid necrosis were seen. Some mononuclear cells were labelled by monoclonal mouse antihuman B cell (CD 20) and T (CD 43) cell antibodies (Dako). The cell infiltrates dissociated otherwise normal muscle fibres (figure, $\mathrm{C}$ ). stitial tissue by mononuclear cells, predomi- 


\section{Discussion}

Muscular symptoms of our patient differed from a typical cramp-fasciculation syndrome in affecting only one limb and by the association with infiltrates of lymphocytes. ${ }^{5}$ Absence of continuous motor unit activity on the EMG was inconsistent with Isaac's syndrome. Absence of central or peripheral nervous system abnormalities, metabolic disease (diabetes mellitus, renal failure), chronic intoxication (coffee, alcohol), arterial ischaemia, and degenerative or dystrophic muscle diseases suggest that symptoms might be related to the infiltration of lymphocytes into the interstitial muscle, which could excite intramuscular nerve terminals.

In this patient, association of atrophy of fat and muscle, and morphea-like changes were characteristic of localised lipoatrophy. This condition includes lipoatrophia annularis, lipoatrophia semicircularis, lipodystrophia centrifugalis, and abdominalis infantilis ${ }^{6}$ and the atrophic connective tissue disease panniculitis. ${ }^{2}$ Several features were not consistent with the diagnosis of linear scleroderma. This is usually an acute solitary unilateral lesion that may involve the skin, subcutaneous fat, vessels, and muscles in sclerosis without extensive atrophy of subcutaneous fat. ${ }^{7}$

Lipodystrophy is usually associated with a variety of systemic conditions, ${ }^{2}$ and occasionally with muscular atrophy or muscle fibre degeneration, ${ }^{8}$ neuropathy, ${ }^{9}$ myopathy, ${ }^{10}$ or dermatomyositis. ${ }^{1}$ Lipodystrophy and interstitial myositis have been described by Palliyath and Garcia in a 54 year old man who experienced a 30 year history of cramps in muscles surrounded by a lipoatrophic skin. ${ }^{3}$ Right lower limb muscles were atrophic and weak. Muscle biopsies showed interstitial lymphocyte infiltration and occasional muscle fibre necrosis. Skin biopsies showed lipoatrophy of subcutaneous tissue with perivascular lymphocyte infiltration and thick collagen bundles in the dermis. Bettley reported localised panatrophy in a 12 year old boy. ${ }^{4}$ The subcutaneous fat of the left buttock had disappeared, ipsilateral gluteal muscles were weak, and there were several areas of atrophic subcutaneous tissues, the skin itself appearing normal. Histological examination showed slight perivascular mononuclear cell infiltration of the skin, without fatty subcutaneous tissue. Muscle fibres were atrophic and areas of coagulation necrosis with patchy lymphocyte infiltration were seen. In our patient, positive antinuclear antibodies and rheumatoid factors, the presence of mononuclear perivascular infiltrates, and the absence of infectious, iatrogenic, or traumatic history suggest an autoimmune origin of both cutaneous and muscle disorders. We did not treat this patient with steroids as regression of the cell infiltration in localised lipoatrophy may occur spontaneously. ${ }^{11}$

We thank P Mielle for technical assistance and Dr Durand for carrying out the electrophysiological examinations.

1 Commens C, O'Neill P, Walker G. Dermatomyositis associated with multifocal lipoatrophy. $7 \mathrm{Am}$ Acad Dermatol 1990;22:966-9.

2 Peters MS, Winkelmann RK. Localised lipoatrophy (atrophic connective tissue disease panniculitis). Arch Dermatol 1980;116:1363-8.

3 Palliyath S, Garcia CA. Multifocal interstitial myositis associated with localised lipoatrophy. Arch Neurol 1982; 39:722-4

4 Bettley FR. Localised panatrophy. Br f Dermatol 1950; 62:330-1.

5 Tahmoush AJ, Alonso RJ, Tamoush GP, HeimanPatterson TD. Cramp-fasciculation syndrome: A treatable hyperexcitable peripheral nerve disorder. Neurology 1991;41:1021-4.

6 Billings JK, Milgraum SS, Gupta AK, Headington JT, Rasmussen JE. Lipoatrophic panniculitis: a possible Rasmussen JE. Lipoatrophic panniculitis: a possible autoimmune inflam

7 Rocco VK, Hurd ER. Scleroderma and scleroderma-like disorders. Semin Arthritis Rheum 1986;16:22-69.

8 Oyanagi K, Sasaki K, Ohama E, Ikuta F, Kawakami A, Miyatani N, et al. An autopsy case of a syndrome with muscular atrophy, decreased subcutaneous fat, skin eruption and hyper g-globulinemia: peculiar vascular changes and muscle fibre degeneration. Acta Neuropathol (Berl) 1987;73:313-9.

9 Gherardi R, Prost C, Chaunu MP, Hauw JJ, Poirier J. Peripheral neuropathy with obstructed vasa-nervorum in a patient with total lipodystrophy, skin eruption and hypergammaglo

10 Bertini E, Bosman C, Cappa M, Turchetta A, Servidei S, Silvestri G, et al. Total lipodystrophy and myopathy: a Silvestri G, et al. Total lipodystrophy and myop

11 Peters MS, Winkelmann RK. The histopathology of localised lipoatrophy. Br f Dermatol 1986;114:27-36. 